\title{
Chromosomal phylogeny of Vampyressine bats (Chiroptera, Phyllostomidae) with description of two new sex chromosome systems
}

Anderson José Baia Gomes', Cleusa Yoshiko Nagamachi', Luis Reginaldo Ribeiro Rodrigues², Thayse Cristine Melo Benathar', Talita Fernanda Augusto Ribas', Patricia Caroline Mary O'Brien ${ }^{3}$, Fengtang Yang ${ }^{4}$, Malcolm Andrew Ferguson-Smith ${ }^{3}$ and Julio Cesar Pieczarka ${ }^{*}$

\begin{abstract}
Background: The subtribe Vampyressina (sensu Baker et al. 2003) encompasses approximately 43 species and seven genera and is a recent and diversified group of New World leaf-nosed bats specialized in fruit eating. The systematics of this group continues to be debated mainly because of the lack of congruence between topologies generated by molecular and morphological data. We analyzed seven species of all genera of vampyressine bats by multidirectional chromosome painting, using whole-chromosome-painting probes from Carollia brevicauda and Phyllostomus hastatus. Phylogenetic analyses were performed using shared discrete chromosomal segments as characters and the Phylogenetic Analysis Using Parsimony (PAUP) software package, using Desmodontinae as outgroup. We also used the Tree Analysis Using New Technology (TNT) software.

Results: The result showed a well-supported phylogeny congruent with molecular topologies regarding the sister taxa relationship of Vampyressa and Mesophylla genera, as well as the close relationship between the genus Chiroderma and Vampyriscus.

Conclusions: Our results supported the hypothesis that all genera of this subtribe have compound sex chromosome systems that originated from an X-autosome translocation, an ancestral condition observed in the Stenodermatinae. Additional rearrangements occurred independently in the genus Vampyressa and Mesophylla yielding the X1X1X2X2/X1X2Y sex chromosome system. This work presents additional data supporting the hypothesis based on molecular studies regarding the polyphyly of the genus Vampyressa and its sister relationship to Mesophylla.
\end{abstract}

Keywords: Chromosome phylogeny, Chromosome painting, Subtribe Vampyressina, Compound sex chromosome system, Sex determination

\footnotetext{
* Correspondence: juliopieczarka@gmail.com

'Laboratório de Citogenética, CEABIO, ICB, Universidade Federal do Pará, Belém, Brazil

Full list of author information is available at the end of the article
}

\section{) Biomed Central}

(C) 2016 The Author(s). Open Access This article is distributed under the terms of the Creative Commons Attribution 4.0 International License (http://creativecommons.org/licenses/by/4.0/), which permits unrestricted use, distribution, and reproduction in any medium, provided you give appropriate credit to the original author(s) and the source, provide a link to the Creative Commons license, and indicate if changes were made. The Creative Commons Public Domain Dedication waiver (http://creativecommons.org/publicdomain/zero/1.0/) applies to the data made available in this article, unless otherwise stated. 


\section{Background}

The subtribe Vampyressina (sensu Baker et al. 2003 [1]) corresponds to a diversified group of New World leafnosed bats specialized in fruit eating. This group encompasses 43 species of phyllostomid genera Platyrrhinus, Vampyrodes, Uroderma, Chiroderma, Vampyriscus, Vampyressa and Mesophylla [2-6]. Intergeneric relationships have been the focus of great debate, with disagreements mainly due to discrepant topologies generated by morphological and molecular data regarding the generic status of Vampyressa and Vampyriscus and their relationships with Chiroderma, Ectophylla and Mesophylla [1, 7-9].

Most studies based on morphological data support the sister taxa relationship between the genera Ectophylla and Mesophylla [7, 10, 11]. However, a study based on cranio-dental characters agrees with the molecular consensus about the close affinity of the genera Mesophylla and Vampyressa [12]. On the other hand, a study of restriction site variation of mitochondrial genes ND3 and ND4 supports the morphological view [13]. A reanalysis based on a direct survey on DNA sequences of these genes agrees with the molecular hypothesis [9].

Cytogenetic studies are agreed on the close relationship between Mesophylla and Vampyressa. All were based on gross chromosome morphology and the shared sex chromosome systems [14-17]. However, no cladistics analysis was made taking into account the different karyotypes of the species within this group.

Chromosome rearrangements are rare genomic changes (sensu [18]) and, because of their Mendelian inheritance, can be used for phylogenetic inferences.
Phylogenetic studies based on chromosome data have contributed to the systematics of many groups of vertebrates, especially in Chiroptera [19-26].

In this paper, we use multidirectional chromosome painting with whole chromosome probes from two phyllostomid bats (Carollia brevicauda and Phyllostomus hastatus), as well as chromosome banding and Fluorescence In Situ Hybridization (FISH) with $18 \mathrm{~S}$ rDNA and telomeric probes, to establish a genome-wide comparative chromosomal map for all genera of Vampyressine bats. Using chromosomal rearrangements as characters, we built a phylogeny that sheds some new light on the evolutionary relationships among these bats.

\section{Methods}

\section{Specimens examined}

Representative species of the subtribe Vampyressina were collected in natural habitats during field expeditions to different places in the Amazon Basin (Table 1). Specimens were maintained in the laboratory with food and water, free from stress, until their necessary euthanasia. This study was specifically approved by the Animal Ethics Committee (Comitê de Ética Animal) from Universidade Federal do Pará (Permit 68-2015) over and above the use of approved general protocols. Voucher specimens were fixed in $10 \%$ formalin, preserved in $70 \%$ ethanol, and deposited in the mammalian collections of the Museu Paraense Emilio Goeldi, Museu de Zoologia da Universidade Federal do Oeste do Pará and Coleção Zoológica do Instituto de Pesquisas do Amapá. JCP has a permanent field permit, number 13,248 from

Table 1 Species analyzed in this work and from Pieczarka et al. (2005, 2013) and Sotero-Caio et al. (2011)

\begin{tabular}{|c|c|c|c|c|c|}
\hline Species & Locality & Sample & $2 n$ & FN & Reference \\
\hline Platyrrhinus incarum, PIN & Belém ( $\left.1^{\circ} 27^{\prime} 08^{\prime \prime} \mathrm{S} ; 48^{\circ} 29^{\prime} 28^{\prime \prime} \mathrm{W}\right)$ & $1 F$ & 30 & 56 & This study \\
\hline Vampyrodes caraccioli, VCA & Belém ( $\left.1^{\circ} 27^{\prime} 08^{\prime \prime} \mathrm{S} ; 48^{\circ} 29^{\prime} 28^{\prime \prime} \mathrm{W}\right)$ & $2 M$ & 30 & 56 & This study \\
\hline Chiroderma villosum, CVI & $\begin{array}{l}\text { Juruti }\left(2^{\circ} 09^{\prime} 18^{\prime \prime} \mathrm{S} ; 56^{\circ} 05^{\prime} 50^{\prime \prime} \mathrm{W}\right) \\
\text { and Santarem }\left(2^{\circ} 26^{\prime} 57^{\prime \prime} \mathrm{S} ; 54^{\circ} 41^{\prime} 59^{\prime \prime} \mathrm{W}\right)\end{array}$ & $1 \mathrm{M}, 1 \mathrm{~F}$ & 26 & 48 & This study \\
\hline Mesophylla macconnelli, MMA & $\begin{array}{l}\text { Faro }\left(1^{\circ} 13^{\prime} 01^{\prime \prime} \mathrm{S} ; 57^{\circ} 44^{\prime} 03^{\prime \prime} \mathrm{W}\right) \\
\text { and Cotriguaçu }\left(9^{\circ} 52^{\prime} 10^{\prime \prime} \mathrm{S} ; 58^{\circ} 33^{\prime} 18^{\prime \prime} \mathrm{W}\right)\end{array}$ & $2 \mathrm{M}, 1 \mathrm{~F}$ & $21 / 22$ & 18 & This study \\
\hline Vampyressa thyone, VTH & Campos Novos $\left(2^{\circ} 22^{\prime} 12^{\prime \prime} \mathrm{N} ; 61^{\circ} 26^{\prime} 08^{\prime \prime} \mathrm{W}\right)$ & $1 \mathrm{M}, 1 \mathrm{~F}$ & $23 / 24$ & 20 & This study \\
\hline Vampyriscus bidens, VBI & $\begin{array}{l}\text { Belém }\left(1^{\circ} 27^{\prime} 08^{\prime \prime} \mathrm{S} ; 48^{\circ} 29^{\prime} 28^{\prime \prime} \mathrm{W}\right) \\
\text { and Faro }\left(1^{\circ} 13^{\prime} 01^{\prime \prime} \mathrm{S} ; 57^{\circ} 44^{\prime} 03^{\prime \prime} \mathrm{W}\right)\end{array}$ & $2 \mathrm{M}, 1 \mathrm{~F}$ & 26 & 48 & This study \\
\hline Vampyriscus brocki, VBR & Lourenço $\left(2^{\circ} 19^{\prime} 49^{\prime \prime} \mathrm{N} ; 51^{\circ} 37^{\prime} 08^{\prime \prime} \mathrm{W}\right)$ & $1 \mathrm{M}$ & 24 & 44 & This study \\
\hline Uroderma magnirostrum, UMA & - & - & 36 & 62 & Pieczarka et al. (2013) \\
\hline Uroderma bilobatum, UBI & - & - & 42 & 50 & Pieczarka et al. (2013) \\
\hline Artibeus obscurus, AOB & - & - & $30 / 31$ & 56 & Pieczarka et al. (2013) \\
\hline Phyllostomus hastatus, PHA & - & - & 32 & 58 & Pieczarka et al. (2005) \\
\hline Carollia brevicauda, CBR & - & - & $20 / 21$ & 36 & Pieczarka et al. (2005) \\
\hline Diphylla ecaudata, DEC & - & - & 32 & 60 & Sotero-Caio et al. (2011) \\
\hline Diaemus youngi, DYO & - & - & 32 & 60 & Sotero-Caio et al. (2011) \\
\hline Desmodus rotundus, DRO & - & - & 28 & 52 & Sotero-Caio et al. (2011) \\
\hline
\end{tabular}


"Instituto Chico Mendes de Conservação da Biodiversidade". The Cytogenetics Laboratory from UFPa has a special permit number 19/2003 from the Ministry of Environment for samples transport and 52/2003 for using the samples for research.

\section{Chromosomal preparation and chromosome banding}

Metaphase spreads were obtained from bone marrow preparations after colchicine treatment, following [27] and [28], as well as from fibroblasts cultured according to [29]. G-banding was performed using trypsin treatment [30] and subsequent incubation in saline solution $(0.5 \times \mathrm{SSC})$ at $60{ }^{\circ} \mathrm{C}$, and staining with Wright's solution [31]. C-banding was carried out according to [32] and Ag-NOR staining followed [33].

\section{Fluorescence in Situ Hybridization (FISH)}

FISH using telomeric probes (All Human Telomere Probes, Oncor) and 18S rDNA probes from Prochilodus argenteus [34] labeled with biotin or digoxigenin by nick translation was performed. Whole-chromosome-specific painting probes from Phyllostomus hastatus (PHA) and Carollia brevicauda (CBR) were obtained from flowsorted chromosomes [25], labeled by DOP-PCR (Degenerate Oligonucleotide-Primed-Polymerase Chain Reaction) amplification [35] and hybridized as previously described $[25,36]$. After hybridization and washing, metaphases were stained with DAPI (4;6-diamidino-2-phenylindole), and images captured using the Axiovision 3.0 software (Carl Zeiss) through an AxioCam MRm coupled to a Zeiss-Axiophot 2 microscope.

\section{Data from literature}

In previous publications $[25,37]$ the species Phyllostomus hastatus, Carollia brevicauda, Artibeus obscurus, Uroderma bilobatum and $U$. magnirostrum were analyzed using the same whole-chromosome probes as used here. We added those data to the present work, and included them in our phylogenetic analysis. Sotero-Caio et al. [38] analyzed Diphylla ecaudata, Diaemus youngi and Desmodus rotundus also using the same probes. These species (Desmondontinae) were used as outgroup on phylogenetic analysis because of their basal position in published molecular phylogenies and because this is a monophyletic subfamily with well supported molecular [1] and chromosomal [38] synapomorphies.

\section{Phylogenetic analysis}

A data matrix was established where the chromosomal rearrangements are the characters under analysis, and discrete chromosomal syntenic blocks are the characters states that reflect the occurrence of rearrangements (Additional file 1: Table S1). The data matrix also included species previously analyzed $[25,37,38]$, and it is available as a supplementary file. Maximum parsimony (MP) analysis was made using PAUP 4.0b10 [39]. A heuristic search to find most parsimonious tree(s) was performed using Tree Bisection Reconnection (TBR) branch-swapping; the bootstrap posterior probability was obtained with one thousand replicates. The Bremer support or "decay index" $[40,41]$ was calculated to verify the inconsistency of the branches in the consensus tree using the software "Tree Analysis Using New Technology" (TNT) version 1.1 [42], freely distributed by the Willi Hennig Society.

\section{Results}

Karyotype description and multidirectional chromosome painting in Chiroderma villosum (CVI)

We analyzed two specimens of C. villosum (Table 1). Both samples show $2 \mathrm{n}=26$ chromosomes and Fundamental Number, FN $=48$ (Fig. 1, CVI). The autosome complement consists solely of biarmed elements (meta, submeta and subtelocentric). The $\mathrm{X}$ is a medium-sized subtelocentric and the $\mathrm{Y}$ is a small acrocentric chromosome. The constitutive heterochromatin $(\mathrm{CH})$ is restricted to centromeric regions of all chromosomes, including the $\mathrm{X}$ (Additional file 2: Figure S1, CVI). FISH using telomeric probes show signals at the distal ends of chromosomes, with dominant strong signals at the centromeric regions of all but pairs $6,8,11$ and the Y (Additional File 3: Figure S2, CVI). Silver staining (not shown) and FISH with $18 \mathrm{~S}$ rDNA revealed a single Nucleolar Organizer Region (NOR) in the short arm of pair 7 (Additional File 3: Figure S2, CVI).

Multidirectional chromosome painting using wholechromosome probes from Carollia brevicauda (CBR) and Phyllostomus hastatus (PHA) revealed 25 and 23 shared conserved syntenic segments, respectively, with the number of syntenic blocks ranging from one to four on each chromosome of CVI (Fig. 1, CVI).

\section{Karyotype description and multidirectional chromosome painting in Vampyriscus bidens (VBI)}

All five specimens of $V$. bidens (Table 1) collected at different sites in the Brazilian Amazon have a $2 n=26$ and $\mathrm{FN}=48$, with all chromosomes biarmed. The $\mathrm{X}$ is subtelocentric and the $\mathrm{Y}$ is acrocentric (Fig. 1, VBI). The $\mathrm{CH}$ is located at the centromeric region of chromosomes and in the proximal region of the $\mathrm{Y}$ chromosome (Additional file 2: Figure S1, VBI). Hybridization with telomeric probes showed signals at the tips of chromosomes and weaker signals at the centromeric regions of some chromosomes in association with the $\mathrm{CH}$ (Additional file 3: Figure S2, VBI). FISH using $18 \mathrm{~S}$ rDNA probes, and silver staining, showed two NOR located on pairs 8 and 9 (Additional file 3: Figure S2, VBI). 


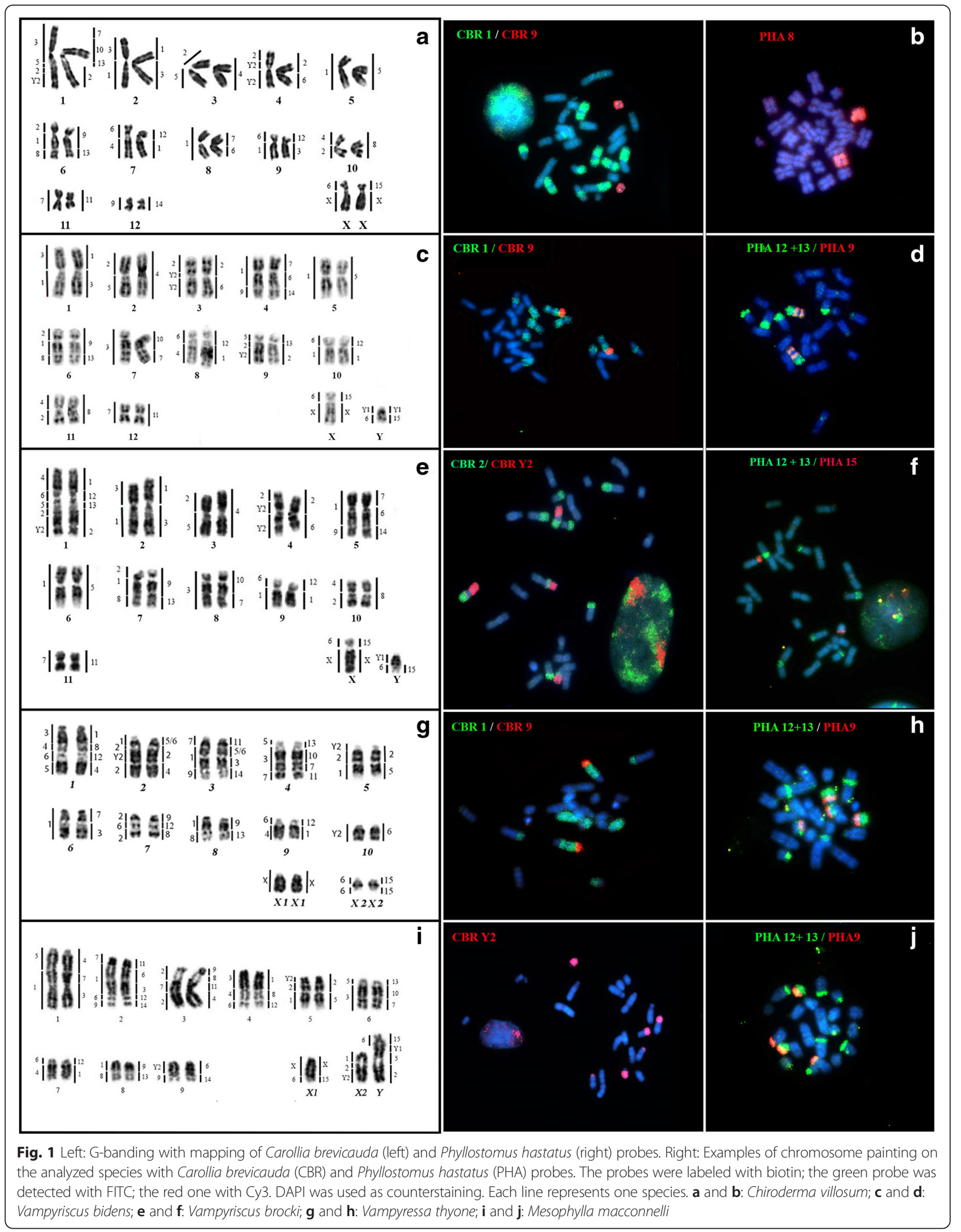


Chromosome painting using CBR and PHA probes revealed 25 and 23 conserved segments on $V$. bidens, respectively. The number of syntenic blocks ranges from one to three in different VBI chromosomes (Fig. 1, VBI).

\section{Karyotype description and multidirectional chromosome painting in Vampyriscus brocki (VBR)}

Vampyriscus brocki collected in Amapá State has a $2 \mathrm{n}=$ 24 and a $\mathrm{FN}=44$ (Fig. 1, VBR). Its karyotype, as in the congeneric VBI, has only biarmed elements (meta, submeta and subtelocentric). The $\mathrm{X}$ is subtelocentric and the $\mathrm{Y}$ is acrocentric. The $\mathrm{CH}$ is located in the pericentromeric regions of chromosomes and the proximal part of $\mathrm{Y}$ (Additional file 2: Figure S1, VBR). FISH signals with telomeric probes were detected at the tips of chromosomes (Additional file 3: Figure S2, VBR). Signals from an $18 \mathrm{~S}$ rDNA probe were detected at the distal portion of the short arm of pairs $5,7,8$, and 9 ; in agreement with silver staining results (Additional file 3: Figure S2, VBR).

Chromosome painting using CBR and PHA probes detect 25 and 23 syntenic segments, respectively. We found a maximum of five segments per chromosome with CBR probes and four with PHA (Fig. 1, VBR).

\section{Karyotype description and multidirectional chromosome painting in Vampyressa thyone (VTH)}

Two specimens of $V$. thyone caught from Serra of Apeú in Roraima state were karyotyped and show a $2 n=24$ complement in the female and $2 \mathrm{n}=23$ in the male, with $\mathrm{FN}=20$ (Fig. 1, VTH). The chromosome complement has only uniarmed pairs, and the sex chromosome system is $\mathrm{X} 1 \mathrm{X} 1 \mathrm{X} 2 \mathrm{X} 2 / \mathrm{X} 1 \mathrm{X} 2 \mathrm{Y}$, so there is one chromosome less in the male karyotype. The $\mathrm{CH}$ is located in small bands in the pericentromeric regions of chromosomes, with one strong $\mathrm{CH}$ block in the interstitial part of $\times 2$ (Additional file 2: Figure S1, VTH). FISH using the telomeric probe showed signals at the tips of chromosomes (Additional file 3: Figure S2, VTH); the $18 \mathrm{~S}$ rDNA probe revealed two NORs on pairs 5 and 9 (Additional file 3: Figure S2, VTH), confirming previous results from silver nitrate (AgNOR) staining.

Chromosome painting revealed 28 and 29 shared segments with CBR and PHA probes, respectively. Results from each set of probes showed a maximum of four syntenic blocks per chromosome in VTH (Fig. 1, VTH).

\section{Karyotype description and multidirectional chromosome painting in Mesophylla macconnelli (MMA)}

We analyzed three specimens of $M$. macconnelli. The diploid number is $2 \mathrm{n}=22$ in female and $2 \mathrm{n}=21$ in males, with the FN $=18$ (Fig. 1, MMA). The chromosomal complement has only uniarmed pairs. The sex chromosome system is $\mathrm{X} 1 \mathrm{X} 1 \mathrm{X} 2 \mathrm{X} 2 / \mathrm{X} 1 \mathrm{X} 2 \mathrm{Y}$. The $\mathrm{CH}$ is present on small bands in the pericentromeric region of the autosomes and on the proximal part of the $\mathrm{Y}$ (Additional file 2: Figure S1, MMA). Probes revealed telomeric signals on the distal ends of all chromosomes (Additional file 3: Figure S2, MMA). Staining with silver nitrate (Ag-NOR) and FISH with $18 \mathrm{~S}$ rDNA probe showed one signal in the distal portion of pair 2 (Additional file 3: Figure S2, MMA).

Chromosome painting on MMA metaphases revealed 28 syntenic segments using probes from CBR, and 30 syntenic segments using probes from PHA. We found a maximum of four segments per chromosome matching CBR probes, and five matching PHA probes (Fig. 1, MMA).

\section{Karyotype description of Platyrrhinus incarum (PIN) and Vampyrodes caraccioli (VCA)}

We analyzed single specimens of $P$. incarum and $V$. caraccioli. Both species have a $2 \mathrm{n}=30, \mathrm{FN}=56$ complement and a Neo-XY sex chromosome system (Additional file 4: Figure S3, PIN and VCA, respectively). The $\mathrm{CH}$ is located in the pericentromeric region of all chromosomes for PIN (Additional File 2: Figure S1, PIN) and in the centromeric regions of the chromosomal complement of VCA (Additional file 2: Figure S1, VCA); additional heterochromatic blocks are present at the distal ends of the short arms of chromosomes 5, 7 and 13 in both species. In PIN, FISH with telomeric probes produced signals at the tips of chromosomes and in the centromeric regions of pair 13 for both species. Additionally, minor signals in some pairs co-located with $\mathrm{CH}$ for PIN (Additional file 3: Figure S2, PIN). In VCA, telomeric probes detect signals at the tips of chromosomes and the centromeric regions of pairs 1, 5 and 13 (Additional file 3: Figure S2, VCA). Probe signals from $18 \mathrm{~S}$ rDNA are located in pair 7, confirming the silver staining in PIN (Additional file 3: Figure S2, PIN), and in chromosome pairs 5 and 7 in VCA.

The banding patterns of these two species (PIN and VCA) are similar to those of Artibeus obscurus (Additional file 4: Figure S3 [37]. The only differences found are a pericentric inversion on pair 5 in PIN, the multiple sex chromosome system in A. obscurus (XX/XY1Y2) and the $\mathrm{Neo-XY}$ in PIN and VCA. Because of the similar Gbanded karyotypes in PIN, VCA, and AOB, we infer that the syntenic groups would be the same as in AOB.

\section{Phylogenetic analyses using chromosome as characters}

We analyzed all representative genera in Vampyressina. Multidirectional chromosome painting identified chromosome homologies and we used a total of 86 discrete chromosomal characters to build a matrix of their presence or absence (Additional File 1 Table). The Maximum Parsimony analysis (MP) resulted in one most parsimonious tree (Tree length $=115$, Consistence index $=0.7478$, retention index $=0.7680$, Homoplasy 
index $=0.2522$ ). The main branch leads to all analyzed species except the outgroup (Bremer index 5, Bootstrap 95). After the split from PHA, the next branch (Bremer index 4, Bootstrap 85) leads to CBR (Carolliinae) and Vampyressina (Stenodermatinae). Then the Stenodermatinae branch (Bremer index 1, Bootstrap 42) splits in two branches. The first branch (Bremer index 3, Bootstrap 88) leads to AOB, PIN, VCA, CVI, VBR and VBI. $A O B$ is the first species to split followed by a branch (Bremer index 1, Bootstrap 77) with a polytomy involving PIN, VCA and a branch leading to CVI (Bremer index 1, Bootstrap 59) followed by VBI and VBR (Bremer index 2, Bootstrap 86). The second branch (Bremer index 1 , Bootstrap 30) consists of the genus Uroderma (Bremer index 6, Bootstrap 99), a sister branch of Mesophylla and Vampyressa (Bremer index 9, Bootstrap 99; Fig. 2).

\section{Discussion}

Genera Platyrrhinus and Vampyrodes

There are only two recognized species in Vampyrodes [6], whereas Platyrrhinus has at least 21 currently described species [5, 43, 44]. Both genera have the same $2 \mathrm{n}=30$ and FN $=56$ karyotype, as well as the Neo-XY sex chromosome system (found in all species described thus far $[14,15,45])$. G-banding patterns have been published only for Platyrrhinus.

In our phylogeny, $P$. incarum and $V$. caracciolli share a polytomy along with the branch corresponding to the genera Vampyriscus and Chiroderma. This polytomy of $P$. incarum and $V$. caracciolli can be explained by their similarity in G-banding pattern and presence of only some autapomorphies. Since these species have no synapomorphies, their precise positions on the phylogeny

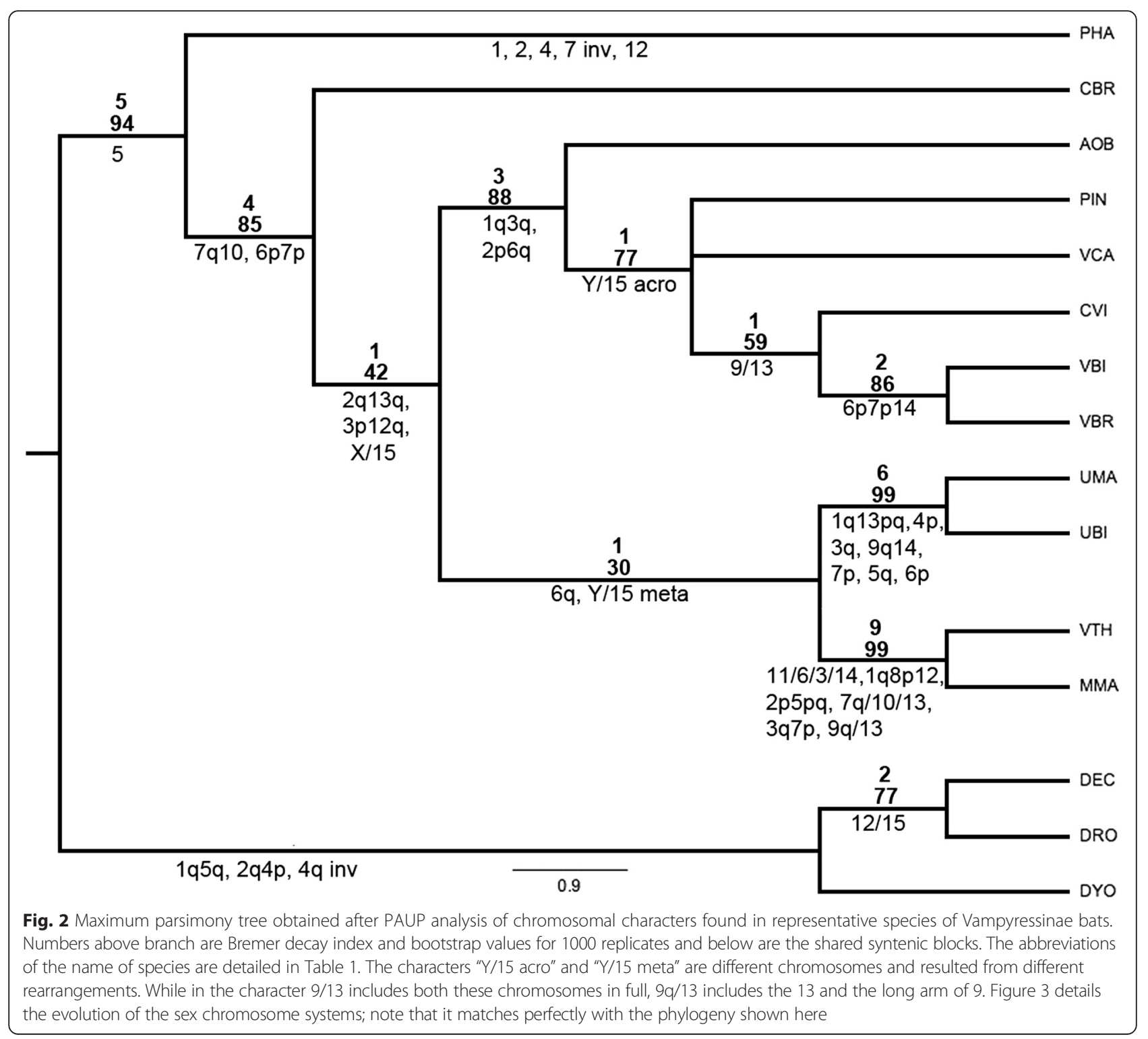


cannot be determined, despite molecular studies suggest a close relationship among Vampyrodes, Platyrrhinus, Vampyriscus and Chiroderma [9]. The chromosomal homeology among these species and Artibeus obscurus supports the hypothesis that the $2 \mathrm{n}=30-31$ karyotype is probably the ancestral condition for the Stenodermatinae [46]. We found only two characteristics supporting the close relationship of Platyrrhinus and Vampyrodes, the shared NOR location observed on pair 7 and an interstitial telomeric site found on pair 13. These characteristics were not included in our phylogeny due to the variability of these marks in the Stenodermatinae. Because of the retention of several ancestral characters and the NOR position, we conclude that the genera Platyrrhinus and Vampyrodes probably are sister taxa, in accordance with most studies based on either the morphological or molecular data [7, 9, 43, 47].

\section{Inter- and intraspecific variation in the genus Uroderma}

Uroderma shows wide karyotypic variation when compared with other species in Stenodermatinae. Three chromosomal races have been described for U. bilobatum (Baker et al. 1972 [48], 1975 [49]). Specimens with $2 n=42$ and FN $=50$ occur in South America, east of the Andes $(2 n=42$ race). Individuals with $2 n=38$ and FN = 44 are distributed on the Atlantic side of Guatemala, Honduras and Yucatan Peninsula of Mexico (Central America) and along the Pacific coast of Colombia and northern Ecuador $(2 \mathrm{n}=38$ race). Specimens with $2 \mathrm{n}=44$ and FN $=48$ occur in the Pacific coast of Central America in El Salvador, Guatemala, Honduras and México (2n = 44 race). A hybrid zone was found in Honduras, but introgression between the two races is low (Hoffmann et al. 2008 [46]). This hybrid zone has been extensively studied since the second half of the $20^{\text {th }}$ century and there is major controversy regarding primary and secondary origins of the zone, the role of selective force in its maintenance, and the amount of gene flow across this zone (Baker et al. 1972 [48], Hoffmann et al. 2008 [46]).

Our data support the hypothesis that the $2 \mathrm{n}=42$ race is distributed throughout South and Central America. Geographic barriers such as the Andean mountains and probably the Gulf of Fonseca (which was under water throughout much of the Pleistocene) separated the race with 42 chromosomes, and gave rise to the 44 and 38 cytotypes (Hoffmann et al. 2008 [46]). There is temporal agreement between the geographic barrier and divergence of the three races that happened around 0.9 to 0.2 Mya (Hoffmann et al. 2008 [46]). Baker et al. (1982 [50]) have proposed the rearrangements that took place to form the cytotypes with 42,44 and 38 chromosomes. We suggest a different set of events: first a pericentric inversion and a fusion/fission differentiated the races with 42 and 44 chromosomes; second a translocation and a tandem fusion from a karyotype with $2 \mathrm{n}=42$ would explain the variation observed in races with 38 chromosomes. Thus, we agree with Hoffmann et al. (2008 [46]) that the ancestral chromosomal race on the deepest branch could have 42 chromosomes, and that the hybrid zone arose later.

\section{Intergeneric relationships among Vampyressina}

Several studies, based mainly on morphological data, support Vampyressa as a monophyletic group (Goodwin 1963 [10], Owen 1987 [11], Wetterer et al. 2000 [7]). However, there is consensus from molecular data regarding its Vampyriscus and Chiroderma, indicating that $V$. bidens, $V$. brocki and $V$. nymphaea can be grouped instead in the genus Vampyriscus and that only V. pusilla, $V$. melissa, and $V$. thyone belong to the genus Vampyressa (Baker et al. 2000 [51], 2003 [1], Porter and Baker 2004 [8], Hoofer and Baker 2006 [9]).

Our results agree with the phylogenetic analysis of nuclear TSHB-I2 sequences made by Hoofer et al. (2008 [52]), strongly supporting the monophyly of Vampyriscus bidens with V. brocki (and their relationship with Chiroderma), the sister taxon relationship between Mesophylla and Vampyressa, as well as the polyphyly of Vampyressa. As pointed out by those authors, these results are in strong agreement with previous molecular studies by Baker et al. (2003 [1]).

Despite our results showing similar pairwise intergeneric relationships as the molecular studies, we found different branching between these groups. Although our analysis recovered a basal branching for the nonStenodermatinae outgroups (PHA and CBR), and the monophyly of Stenodermatinae, the position of $\mathrm{AOB}$ within the Vampyressina disagrees with molecular and morphological data. Nevertheless, the presented topology is strongly supported by chromosomal data, namely the rearrangements shown in Fig. 2. For instance, both branches show an Y/15 translocation, but the resulting chromosomes have different morphologies, suggesting that they have different origins. Alternatively, they could have undergone further rearrangements since their divergence from their most recent common ancestor or be a case of hemiplasy (Robison et al. 2008 [53]) where the ancestral population could have contained both forms in polymorphic fashion, each cytotype becoming fixed in a different branch. This fusion is an easily recurrent rearrangement, since all the species in both branches have an $\mathrm{X} / 15$ fusion. During meiosis the $\mathrm{Y}$ and the free autosome (the other 15) will be very close because of pairing with the $\mathrm{X} / 15$, thus increasing the possibility that any chromatin break in the $\mathrm{Y}$ and free 15 would result in a fusion. Also, Artibeus obscurus has the $\mathrm{X} / 15$ fusion only, but not $\mathrm{Y} / 15$. This genus is divided into two groups, large and small Artibeus. For some 
authors the large should be organized in the subgenus Artibeus and small in Dermanura (Redondo et al. 2008 [54]; Wilson \& Reader, 2005 [55]) while others consider that these groups are distinct genera (Baker et al. 2003 [1]; Solari et al. 2009 [56]). All karyotypes already described for large Artibeus have a XY1Y2 system, but there is variation in Dermanura: toltecus and aztecus have a XY1Y2 system (Baker, 1973 [57]) while watsoni and phaeotis have neo-XY (Baker, 1967 [58]; Hsu et al. 1968 [59]). A. cinereus has a XY1Y2 system in Central America (Baker, 1973 [57]) and neo-XY in South America (Souza \& Araujo, 1990 [45]; Noronha et al. 2010 [60]). The neo-XY in Dermanura represents a third fusion between the $\mathrm{Y}$ and 15 .

We tested many data matrices, using both PAUP and TNT, and all the resulting trees have the same branching pattern, suggesting that Vampyressina could be a polyphyletic subtribe resulting from convergent evolution, in a similar fashion to that observed in the subfamilies of nectarivorous bats (Ribeiro et al. 2003 [61]; Sotero-Caio et al. 2013 [62]). Although some branches have low bootstrap values, the decay index values give them a good support. Whereas the bootstrap is a more quantitative test, the Bremer index is qualitative, as is chromosomal variation.
Sex chromosome evolution in the subtribe Vampyressina Translocations between an autosome and a sex chromosome are rarely fixed in speciation because of meiotic problems, including inactivation of the homologues fused to the X chromosome (Mattei et al. 1982 [63]). Phyllostomidae is an exception to this rule where there are subfamilies with most or all species having multiple or compound sex chromosome systems (e.g., Stenodermatinae and Carolliinae - Hsu et al. 1968 [59], Tuker 1986 [64]). In this work, we present for the first time a hypothesis explaining the sex chromosome evolution in the Vampyressina and describe the events that gave rise to the sex chromosome systems observed in M. macconnelli and $V$. thyone.

We suggest that all species in the Vampyressina have a Neo-XY sex chromosome system and that the different sex chromosome systems as seen in Mesophylla and Vampyressa represent a derived character state (Fig. 3). In the genus Mesophylla, the sex chromosome system has evolved from a Neo-XY system after a further translocation of the compound $\mathrm{Y}$ with an autosome that led to a Neo-X1X2Y. To our knowledge, it has never been described before in mammals. In $V$. thyone, the sex chromosomes system evolved after the fission of the

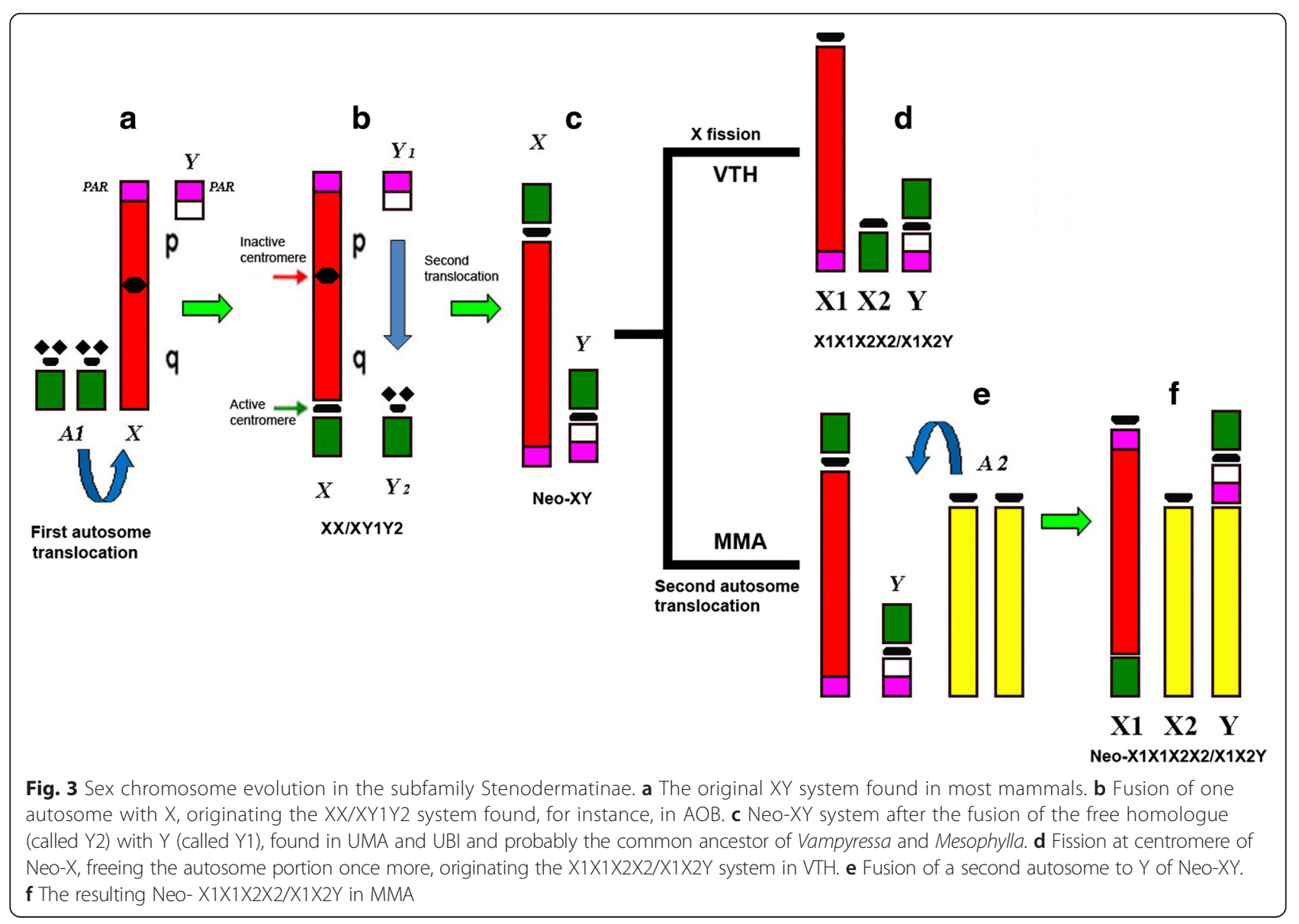


autosome (corresponding to PHA15) that was translocated to the $\mathrm{X}$ chromosome in the ancestral karyotype of Stenodermatinae. As the Y-autosome translocation also involves an autosome, its free homologue would be X2.

\section{Conclusions}

Our comparative analysis of all genera of vampyressine using a cytogenomic approach confirmed the molecular phylogeny previously described for this group, being independent evidence supporting that phylogeny. Our results also confirm that all genera of this subtribe have compound sex chromosome systems that originated from an X-autosome translocation, an ancestral condition observed in the Stenodermatinae subfamily. In Mesophylla we found a sex chromosome system never described before in mammals. We were able to trace all the chromosomal sex system evolution in vampyressine and show that it mirrors the phylogeny of this group. This work presents additional data supporting Hoofer \& Baker (2006 [9]) hypothesis based on molecular studies regarding the polyphyly of the genus Vampyressa and its sister relationship to Mesophylla.

\section{Additional files}

Additional file 1: Table S1. Vampyressina, Basic Data Matrix using PHA chromosome numbering as reference (DOC $198 \mathrm{~kb}$ )

Additional file 2: Figure S1. C-banding patterns on Chiroderma villosum (CVI); Vampyriscus bidens (VBI); Vampyressa thyone (VTH); Mesophylla macconnelli (MMA); Vampyrodes caraccioli (VCA); Platyrrhinus incarum (PIN); Vampyriscus brocki (VBR). (JPG 1943 kb)

Additional file 3: Figure S2. Fish with telomeric (left) and rDNA probes (right) in Chiroderma villosum (CVI); Vampyriscus bidens (VBI); Vampyriscus brocki (VBR); Vampyressa thyone (VTH); Mesophylla macconnelli (MMA); Platyrrhinus incarum (PIN); Vampyrodes caraccioli (VCA). (JPG 5731 kb)

Additional file 4: Figure S3. G-banding patterns of Platyrrhinus incarum (PIN) and Vampyrodes caraccioli (VCA). (JPG 807 kb)

\begin{abstract}
Abbreviations
2n, diploid number; Ag-NOR, silver nitrate staining; $A O B$, Artibeus obscurus; $\mathrm{CBR}$, Carollia brevicauda; $\mathrm{CH}$, constitutive heterochromatin; $\mathrm{CVI}$, Chiroderma villosum; DAPI, 4', 6-diamidino-2-phenylindole; DEC, Diphylla ecaudata; DRO, Desmodus rotundus; DOP-PCR, Degenerate oligonucleotide-primed-polymerase chain reaction; DYO, Diaemus youngi; FISH, Fluorescence In Situ Hybridization; FN, Fundamental Number; MP, Maximum parsimony ; NOR, Nucleolar organizer region; PHA, Phyllostomus hastatus; PIN, Platyrrhinus incarum; MMA, Mesophylla macconnelli; PAUP, Phylogenetic analysis using parsimony; SSC, Saline sodium citrate; TBR, tree bisection reconnection; TNT, Tree analysis using new technology; VBI, Vampyriscus bidens; VBR, Vampyriscus brocki; VCA, Vampyrodes caraccioli; VTH, Vampyressa thyone
\end{abstract}

\section{Acknowledgements}

We thank Manoel Rodrigues (Juris Ambientes Consultores), Flávio Eduardo Pimenta (Aotus Consultoria) for helping us in the field expedition to the area of Alcoa's Juruti Bauxite mine. We thank Biodinamica-Rio, Aotus Consultoria, Eloiza Soarez, Fabio Sarmento, Fabio Augusto and Ramon Araujo for helping us with the expedition from Oriximina (Pará state) to Cariri (Amazonas state), Cibele Gomes de Sotero-Caio for the critical review of the manuscript. This study is part of the Doctoral thesis of AJBG who was a recipient of a CAPES (Conselho Aperfeiçoamento de Pessoal de Nível Superior) Scholarship in Genetics and Molecular Biology, UFPA.

\section{Funding}

Conselho Nacional de Desenvolvimento Científico e Tecnológico (CNPq) and the Fundação Amazônia Paraense (FAPESPA) on projects coordinated by CYN (Edital Universal, TO 064/2008; Edital BIONORTE-CNPq, Proc 552032/2010-7; Edital BIONORTE-FAPESPA, ICAAF 007/2011); Coordenação de Aperfeiçoamento de Pessoal de Nível Superior (CAPES), on a Edital Pró-Amazônia project coordinated by CYN; the FAPESPA (Edital Vale - ICAAF 064/2011) and Banco Nacional de Desenvolvimento Economico e Social - BNDES (Operação 2.318.697.0001) on a project coordinated by JCP; CYN (308428/2013-7) and JCP (308401/2013-1) are granted as CNPq researchers.

Availability of data and materials

All the data supporting your findings are contained within the manuscript.

\section{Authors' contributions}

AJBG collected the samples, collaborated in all of the cytogenetic data and phylogenetic analyze, undertook the bibliographic review. CYN collaborated in all cytogenetic procedures and analyzes. LRRR collected part of the samples, collaborated with cytogenetic data and reviewed the paper. TCMB helped conceive the study and participated in developing the laboratory techniques. TFAR participated in the cytogenetic and phylogenetic analyses, and reviewed the manuscript. PCMOB and FY helped on writing the paper and discussed the data. MAFS helped on the development of the probes, participated in the cytogenetic analyses, and reviewed the manuscript. JCP helped conceive the study and participated in developing the laboratory techniques, and coordinated the writing of this paper. All authors read and approved the final manuscript.

\section{Competing interests}

The authors declare that they have no competing interests.

\section{Consent to publish}

Not applicable.

\section{Ethics approval and consent to participate}

The necessary euthanasia occurred in accordance with animal welfare guidelines established by the Animal Ethics Committee (Comitê de Ética Animal) from Universidade Federal do Pará (Permit 68-2015). JCP has a permanent field permit, number 13248 from "Instituto Chico Mendes de Conservação da Biodiversidade". The Cytogenetics Laboratory from UFPa has a special permit number 19/2003 from the Ministry of Environment for samples transport and 52/2003 for using the samples for research.

\section{Author details}

'Laboratório de Citogenética, CEABIO, ICB, Universidade Federal do Pará, Belém, Brazil. "2Laboratório de Genética e Biodiversidade, ICED, Universidade Federal do Oeste do Pará, Santarém, Brazil. ${ }^{3}$ Cambridge Resource Centre for Comparative Genomics, University of Cambridge Department of Veterinary Medicine, Cambridge, UK. ${ }^{4}$ Cytogenetics Facility, Welcome Trust Sanger Institute, Hinxton, South Cambridgeshire, UK.

Received: 29 October 2015 Accepted: 23 May 2016

Published online: 04 June 2016

\section{References}

1. Baker RJ, Hoofer SR, Porter CA, Van Den Bussche RA. Diversification among New World leaf-nosed bats: an evolutionary hypothesis and classification inferred from digenomic congruence of DNA sequence. Lubbock, Texas, USA: Occasional Papers of Museum Texas Tech University. 2003; 230:1-32.

2. Mantilla-Meluk H. Defining species and species boundaries in Uroderma (Chiroptera: Phyllostomidae) with a description of a new species. Ocassional papers. Lubbock, Texas, USA: Texas Tech University. 2014;325:1-29.

3. Taddei VA, Lim BK. A new species of Chiroderma (Chiroptera: Phyllostomidae) from Northeastern Brazil. Braz J Biol. 2010;70(2):381-6.

4. Tavares VC, Gardner AL, Ramírez-Chaves HE, Velazco PM. Systematics of Vampyressa melissa Thomas, 1926 (Chiroptera: Phyllostomidae), with descriptions of two new species of Vampyressa. Am Mus Novit. 2014;3813:27.

5. Velazco PM, Lim BK. A new species of broad-nosed bat Platyrrhinus Saussure, 1860 (Chiropter: Phyllostomidae) from the Guianan Shield. Zootaxa. 2014;3796:175-93. 
6. Velazco PM, Simmons NB. Systematics and Taxonomy of Great Striped-Faced Bats of the Genus Vampyrodes Thomas, 1900 (Chiroptera: Phyllostomidae). Am Mus Novit. 2011;3710:1-35.

7. Wetterer AL, Rockman MV, Simmons NB. Phylogeny of phyllostomid bats (Mammalia: Chiroptera): data from diverse morphological systems, sex chromosomes and restriction sites. New York, NY, USA: Bulletin of the American Museum of Natural History. 2000;248:1-200.

8. Porter CA, Baker RJ. Systematics of Vampyressa and related genera of phyllostomid bats as determined by cytochrome- b sequences. J Mammal. 2004:85:126-32.

9. Hoofer SR, Baker RJ. Molecular systematic of Vampyressine bats (Phyllostomidae: Stenodermatinae) with comparison of direct and indirect surveys of mitochondrial DNA variation. MolPhylogenet Evol. 2006;39:424-38

10. Goodwin GG. American bats of genus Vampyressa, with the description of a new species. Am Mus Novit. 1963;2125:1-24.

11. Owen RD. Phylogenetic analyses of the bat subfamily Stenodermatinae (Mammalia: Chiroptera). Lubbock, Texas, USA: Special Publications of Museum Texas Tech University. 1987;26:1-65.

12. Starrett A, Casebeer RS. Records of bats from Costa Rica. Contrib. Sci., Los Angeles Co. Mus. 1968;148:1-21.

13. Lim BK, Pedro WA, Passos FC. Differentiation and species status of the Neotropical yellow-eared bats Vampyressa pusilla and V. thyone (Phyllostomidae) with a molecular phylogeny and review of the genus. Acta Chiropterologica. 2003;5:15-29.

14. Baker RJ, Hsu TC. Further studies on the sex chromosome system of the American leaf-nosed bat (Chiroptera-Phylostomatidae). Cytogenetics. 1970; 9:131-8.

15. Baker RJ, Genoways HH, Bleier WJ, Warner W. Cytotypes and morphometrics of two phyllostomatid bats, Micronycteris hirsuta and Vampyressa pusilla. Lubbock, Texas, USA: Occasional Papers of Museum, Texas Tech University. 1973a; 17:1-10.

16. Greenbaum IF, Baker RJ, Wilson DE. Evolutionary implications of the karyotypes of the Stenodermine genera Ardops, Ariteus, Phyllops, and Ectophylla. Los Angeles, California: Bulletin of the Southern Academy of Sciences. 1975;74:156-159.

17. Gardner AL. Chromosomal variation in Vampyressa and a review of chromosomal evolution in the Phyllostomidae (Chiroptera). Syst Zool. 1977;26:300-18.

18. Rokas A, Holland PWH. Rare genomic changes as a tool for phylogenetics. Science. 2000;15:454-9.

19. Volleth M, Heller KG, Pfeiffer RA, Hameister H. Comparative ZOO-FISH analysis in bats elucidates the phylogenetic relationships between Megachiroptera and five microchiropteran families. Chromosom Res. 2002;10:477-97.

20. Volleth M, Yang F, Müller S. High resolution chromosome painting reveals the first signature for the chiropteran suborder Pteropodiformes (Mammalia: Chiroptera). Chromosom Res. 2011;19(4):507-19.

21. Ao $L$ et al. Karyotypic evolution and phylogenetic relationships in the order Chiroptera as revealed by G-banding comparison and chromosome painting. Chromosom Res. 2007;15:257-68.

22. Mao X et al. Karyotype evolution in Rhinolophus bats (Rhinolophidae, Chiroptera) illuminated by cross-species chromosome painting and G-banded comparison. Chromosom Res. 2007;15:2-14.

23. Mao X et al. Comparative cytogenetics of bats (Chiroptera): The prevalence of Robertsonian translocation limits the power of chromosomal characters in resolving interfamily phylogenetic relationships. Chromosom Res. 2008;16:155-70.

24. Richards LR, Rambau RV, Lamb JM, et al. Cross-species chromosome painting in bats from Madagascar: the contribution of Myzopodidae to revealing ancestral syntenies in Chiroptera. Chromosom Res. 2010;18:635-53.

25. Pieczarka JC, Nagamachi CY, O'Brien PCM, et al. Reciprocal chromosome painting between two South American bats: Carollia brevicauda and Phyllostomus hastatus (Phyllostomidae, Chiroptera). Chromosom Res. 2005;13:349-7.

26. Ribas TAF, Rodrigues $L R R$, Nagamachi $C Y$, et al. Phylogenetic reconstruction by cross-species chromosome painting and G-banding in four species of Phyllostomini Tribe (Chiroptera, Phyllostomidae) in the Brazilian Amazon: An independent evidence for monophyly. PLoS ONE. 2015;10(3), e0122845. doi: 10.1371/journal.pone.0122845.

27. Armada JL, Souza CS, Canavez FC. An improved procedure to obtain chromosome preparations of bats. Revista da Universidade Rural, Série Ciência da Vida. 1996;18(1-2):73-5.

28. Baker RJ, Hamilton M, Parish DA. Preparations of Mammalian karyotypes under field conditions. Lubbock, Texas, USA: Occasional Papers of Museum Texas Tech University. 2003;228:17.
29. Moratelli R, Andrade CM, Armada JLA. A technique to obtain fibroblast cells from skin biopsies of living bats (Chiroptera) for cytogenetic studies. Genet Mol Res. 2002;2:128-30.

30. Seabright M. A rapid banding technique for human chromosome. Lancet. 1971;2:971-2.

31. Verma RS, Babu A. Human chromosomes: Principles and techniques. 2ath ed. Inc. Health profession division: McGraw-Hill; 1995.

32. Sumner AT. A simple technique for demonstrating centromeric heterochromatin. Exp Cell Res. 1972;75:304-6.

33. Howell WM, Black DA. Controlled silver staining of Nucleolar Organizer Regions with protective colloidal developer: a 1-step method. Experientia. 1980;36:1014-5.

34. Hatanaka T, Galetti PM. Mapping of the $18 \mathrm{~S}$ and $5 \mathrm{~S}$ ribosomal RNA genes in the fish Prochilodus argenteus Agassiz, 1829 (Characiformes, Prochilodontidae). Genetica. 2004;122:239-44.

35. Telenius H, Ponder BAJ, Tunnacliffe A, Pelmear AH, Carter NP, FergusonSmith MA, Behmel A, Nordenskjöld M, Pfragner R. Cytogenetic analysis by chromosome painting using DOP-PCR amplified flow-sorted chromosomes. Genes Chromosom Cancer. 1992;4:257-63.

36. Yang F, Carter NP, Shi L, Ferguson-Smith MA. A comparative study of karyotypes of muntjacs by chromosome painting. Chromosoma. 1995;103:642-52.

37. Pieczarka JC, Gomes AJB, Nagamachi CY, Rocha DCC, Rissino JD, et al. A phylogenetic analysis using multidirectional chromosome painting of three species (Uroderma magnirostrum, U. bilobatum and Artibeus obscurus) of subfamily Stenodermatinae (Chiroptera-Phyllostomidae). Chromosom Res. 2013;21:383-92.

38. Sotero-Caio CG, Pieczarka JC, Nagamachi CY, et al. Chromosomal Homologies among Vampire Bats Revealed by Chromosome Painting (Phyllostomidae, Chiroptera). Cytogenet Genome Res. 2011;132:156-64.

39. Swoford DL. PAUP*. Phylogenetic Analysis Using Parsimony (and Other Methods). Version 4. Sunderland, Massachusetts.: Sinauer Associates; 2002.

40. Bremer $\mathrm{K}$. The limits of amino sequence data in angiosperm phylogenetic reconstruction. Evolution. 1988:42:795-803.

41. Bremer K. Branch support and tree stability. Cladistics. 1994;10:295-304.

42. Goloboff PA, Farris JS, Nixon KC. TNT, a free program for phylogenetic analysis. Cladistics. 2008;24:774-86.

43. Velazco PM. Morphological Phylogeny of the Bat Genus Platyrrhinus Saussure, 1860 (Chiroptera: Phyllostomidae) with the Description of Four New Species. Fieldiana Zool. 2005;105:1-53.

44. Solari S. Martínez-Arias. Cambios recientes en la sistemática y taxonomía de murciélagos Neotropicales (Mammalia: Chiroptera). Therya. 2014;5(1):167-96.

45. Souza MJ, Araújo MCP. Conservative pattern of the G-bands and diversity of C-banding patterns and NORs in Stenodermatinae (ChiropteraPhyllostomatidae). Revista Brasileira de Genética. 1990;13:255-68.

46. Hoffmann FG, Hoofer SR, Baker RJ. Molecular dating of the diversification of Phyllostominae bats based on nuclear and mitochondrial DNA sequences. Mol Phylogenet Evol. 2008;49(2):653-8.

47. Velazco PM, Patterson BD. Phylogenetics and biogeography of the broadnosed bats, genus Platyrrhinus (Chiroptera: Phyllostomidae). Mol Phylogenet Evol. 2008:49:749-59.

48. Baker RJ, Atchley WR, McDaniel VR. Karyology and morphometrics of Peter's tent-making bat, Uroderma bilobatum Peters (Chiroptera: Phyllostomatidae). Syst Zool. 1972;21:414-29.

49. Baker RJ, Bleier WJ, Atchley WR. A contact zone between karyotipically characterized taxa of Uroderma bilobatum (Mammalia: Chiroptera). Syst Zool. 1975;24:133-42.

50. Baker RJ, Haiduk MW, Robbins LW, Cadena A, Koop BF. Chromosomal studies of South American bats and their systematic implications. In: Mammalian Biology in South America. Vol. 4. Mares, MA, Genoways HH (Eds.) Special publication Series, Pymatuning Laboratory of Ecology, University of Pittsburg p. 303-327. 1982.

51. Baker RJ, Porter CA, Patton JC, Van Den Bussche RA. Systematics of bats of the family Phyllostomidae based on RAG2 DNA sequences. Lubbock, Texas, USA: Occasional papers, Museum of Texas Tech University. 2000; 202:1-16.

52. Hoofer SR, Flanary WE, Bull RJ, Baker RJ. Phylogenetic relationships of vampyressine bats and allies (Phyllostomidae: Stenodermatinae) based on DNA sequences of a nuclear intron (TSHB-12). Mol Phylogenet Evol. 2008;47:870-6.

53. Robinson TJ, Ruiz-Herrera A, Avise JC. Hemiplasy and homoplasy in the karyotypic phylogenies of mammals. PNAS. 2008;105(38):14477-81.

54. Redondo RAF, Brina LPS, Silva RF, Ditchfield AD, Santos FR. Molecular systematics of the genus Artibeus (Chiroptera: Phyllostomidae). Mol Phylogenet Evol. 2008;49:44-58. 
55. Wilson DE, Reader DEA. Mammal Species of the World: A Taxonomic and Geographic Reference, Volume 1. Baltimore, Maryland, USA: JHU Press. 2005.

56. Solari S, Hoofer SR, Larsen PA, Brown AD, Bull RJ, Guerrero JA, Ortega J, Carrera JP, Bradley RD, Baker RJ. Operational criteria for genetically defined species: analysis of the diversification of the small fruit-eating bats, Dermanura (Phyllostomidae: Stenodermatinae). Acta Chiropterologica. 2009;1 1(2):279-88.

57. Barker RJ. Comparative cytogenetics of the New World leaf-nosed bats (Phyllostomidae). Period Biol. 1973;75:37-45.

58. Barker RJ. Karyotypes of bats of the family Phyllostomidae and their taxonomic implications. Southwest Nat. 1967;12(4):407-28.

59. Hsu TC, Baker RJ, Utakoji T. The multiple sex chromosome system of American leaf-nosed bats (Chiroptera, Phyllostomidae). Cytogenetics. 1968;7:27-38.

60. Noronha RCR, Nagamachi CY, O'Brien PCM, Ferguson-Smith MA, Pieczarka JC. Meiotic analysis of XX/XY and neo-XX/XY sex chromosomes in Phyllostomidae by cross-species chromosome painting revealing a common chromosome 15-XY rearrangement in Stenodermatinae. Chromosom Res. 2010;18:667-76.

61. Ribeiro NAB, Nagamachi CY, Pieczarka JC, et al. Cytogenetic analysis in species of the Subfamily Glossophaginae (Phyllostomidae, Chiroptera) supports a polyphyletic origin. Caryologia. 2003;56(1):85-96.

62. Sotero-Caio CG, Volleth M, Gollahon LS, et al. Chromosomal evolution among leaf-nosed nectarivorous bats - evidence from cross-species chromosome painting (Phyllostomidae, Chiroptera). BMC Evol Biol. 2013;13:276.

63. Mattei MG, Mattei JF, Ayme S, Giraud F. X-autosome translocations: Cytogenetic characteristics and their consequences. Hum Genet. 1982; 61(4):295-309.

64. Tucker PK. Sex chromosome-autosome translocations in the leaf-nosed bats, family Phyllostomidae. I. Mitotic analyses of the subfamilies Sternodermatinae and Phyllostominae. Cytogenet Cell Genet. 1986;43:19-27.

\section{Submit your next manuscript to BioMed Central and we will help you at every step:}

- We accept pre-submission inquiries

- Our selector tool helps you to find the most relevant journal

- We provide round the clock customer support

- Convenient online submission

- Thorough peer review

- Inclusion in PubMed and all major indexing services

- Maximum visibility for your research

Submit your manuscript at www.biomedcentral.com/submit 